\title{
Oxidative stress in microorganisms exposed to iron nanoparticles
}

\author{
A. Sevcu \& M. Cernik \\ Institute of New Technologies and Applied Informatics, \\ Technical University of Liberec, Czech Republic
}

\begin{abstract}
Engineered iron nanoparticles, with sizes smaller than $100 \mathrm{~nm}$, have been of high concern because of their promising capability in environmental remediation. Nanoparticles based on zero-valent iron (nZVI) have the potential not only to migrate in the environment and interact with pollutants but also influence the living organisms by direct impact or by changes of groundwater parameters. The basis of many food chains is dependent on the benthic and soil flora and fauna. In general, nZVI can significantly influence the soil microbial diversity, interact with ions in the soil, form non-toxic complex salts and/or be adsorbed. Moreover, nanoparticles could have indirect effect on microorganisms via changes in bioavailability of essential compounds. Iron can convert less reactive hydrogen peroxide to more reactive oxygen species (ROS) via the Fenton reaction. ROS that includes superoxide radicals or hydrogen peroxide are also generated as a by-product of aerobic metabolism, because aerobic organisms use oxygen as a terminal electron acceptor when producing energy. Mitochondrial electron transport reduces $95 \%$ of $\mathrm{O}_{2}$ to water, but the remaining $5 \%$ of $\mathrm{O}_{2}$ is reduced to superoxide radical. Unnaturally elevated concentrations of ROS in microbial cell can result in a situation known as the oxidative stress. Production of ROS constitutes a severe risk to photosynthetic organisms such as cyanobacteria and algae, because a common source of superoxide radicals is photosynthesis. Mitochondria and chloroplasts have intensive electron fluxes which also contain higher oxygen and metal ion concentrations and therefore both organelles are more vulnerable to oxidative stress.
\end{abstract}

Keywords: nanotoxicology, zero-valent iron nanoparticles, oxidative stress, reactive oxygen species. 


\section{Introduction}

Engineered iron nanoparticles, with sizes smaller than $100 \mathrm{~nm}$, have been of high concern because of their promising capability in environmental remediation of waters, soils and sediments [1-3]. It is well known that nanoiron has the potential to migrate in the environment and interact not only with pollutant chemicals but also with living organisms [4]. The basis of many food chains is dependent on the benthic and soil flora and fauna, which could be affected. On the other hand, Shah and Belozerova [5] did not found significant influence of various nanoparticles on soil microbial diversity over a 15-day exposition. However, the nanoparticles probably interacted with ions in the soil and formed non-toxic complexed salts or were adsorbed on the organic compounds [6]. Still, this study showed slight diversity in particular parameters within differently treated soil samples that might cause long term trends [5]. Moreover, nanoparticles could have indirect effect on microorganisms via changes in bioavailability of toxic or essential compounds [7].

Iron in its reduced form can convert less reactive hydrogen peroxide to more reactive oxygen species (ROS) - hydroxyl radicals and ferryl iron via the Fenton reaction [8]. ROS that includes superoxide radicals or hydrogen peroxide are also generated as a by-product of aerobic metabolism, because aerobic organisms use oxygen as a terminal electron acceptor when producing energy. Mitochondrial electron transport reduces $95 \%$ of $\mathrm{O}_{2}$ to water, but the remaining $5 \%$ of $\mathrm{O}_{2}$ is reduced to superoxide radical [9, 10]. Superoxide radicals are normally eliminated by dismutation to hydrogen peroxide which is further reduced to water [9]. However, unnaturally elevated concentrations of ROS in microbial cell can result in a situation known as oxidative stress $[11,12]$.

Cells under severe oxidative stress show various dysfunctions of membrane lipids, proteins and DNA $[3,11]$. Dealing with oxidative stress, microorganisms have to promptly response with production of repair enzymes and antioxidants. Further, strict regulation of iron assimilation prevents an excess of free intracellular iron that could lead to oxidative stress [13].

This paper focuses on up-to-date studies on iron-induced intracellular changes leading to oxidative stress in microorganisms. Because of very scarce information on nZVI effect on microorganisms, studies on other organisms and cell cultures are briefly mentioned in this review.

\section{Zero-valent iron nanoparticles}

\subsection{Nanoiron production and its basic reactions in water}

The zero-valent nanoiron is produced in a wet process by a reduction of solutions of ferric or ferrous salts with sodium borohydride or in a dry process by a reduction of ferric salts by hydrogen at higher temperature. Nanoiron is very reactive in water and is a typical electron-donator for which is widely used in pollutant decontamination. In comparison with microscale iron, nanoiron is smaller than $100 \mathrm{~nm}$ and has large specific surface area and therefore higher 
reactivity [2, 12]. For example, the rate of reduction of toxic hexavalent chromium using nanoiron is 7-12 times faster than using an equivalent amount of iron powder [14].

Manufactured iron particles have a core-shell structure. The core consists of zero-valent or metallic iron while the $\mathrm{Fe}^{2+}$ and $\mathrm{Fe}^{3+}$ oxide shell is formed as a result of oxidation of the metallic iron and protect the core iron from rapid oxidation [2]. Moreover, lately, nZVI has been amended with various compounds to improve its mobility and reactivity under different environmental conditions. Nanoiron surface has been coated by polymers, polyelectrolytes, surfactants or the nanoparticles can be bimetallic [15-17].

Generally, iron nanoparticles are very reactive species and their surface properties change rapidly over time and environmental conditions. Following reactions describing speciation of surface oxides and hydroxides of nanoiron particles are biologically important [2]:

$$
\begin{gathered}
2 \mathrm{Fe}^{0}+\mathrm{O}_{2}+2 \mathrm{H}_{2} \mathrm{O} \rightarrow 2 \mathrm{Fe}^{2+}+4 \mathrm{OH}^{-} \\
\mathrm{Fe}^{0}+2 \mathrm{H}_{2} \mathrm{O} \rightarrow \mathrm{Fe}^{2+}+\mathrm{H}_{2}+2 \mathrm{OH}^{-} \\
\mathrm{Fe}^{2+} \text { can be further oxidized to } \mathrm{Fe}^{3+}: \\
4 \mathrm{Fe}^{2+}+4 \mathrm{H}^{+}+\mathrm{O}_{2} \rightarrow 4 \mathrm{Fe}^{3+}+2 \mathrm{H}_{2} \mathrm{O} \\
\mathrm{Fe}^{3+} \text { reacts with } \mathrm{OH}^{-} \text {or } \mathrm{H}_{2} \mathrm{O}: \\
\mathrm{Fe}^{3+}+3 \mathrm{OH} \rightarrow \mathrm{Fe}(\mathrm{OH})_{3} \\
\mathrm{Fe}^{3+}+2 \mathrm{H}_{2} \mathrm{O} \rightarrow \mathrm{FeOOH}+3 \mathrm{H}^{+}
\end{gathered}
$$

$\mathrm{Fe}(\mathrm{OH})_{3}$ can also dehydrate to form $\mathrm{FeOOH}$ :

$$
\mathrm{Fe}(\mathrm{OH})_{3}+3 \mathrm{H}^{+} \rightarrow \mathrm{FeOOH}+\mathrm{H}_{2} \mathrm{O}
$$

Nanoiron also corrodes in presence of oxygen and water (Reaction 1 and 2), which leads to a $\mathrm{pH}$ increase.

\subsection{Environmental risk}

Nanoiron has been increasingly applied for remediation of polychlorinated biphenyls, organochlorine pesticides or heavy metals such as chromium or arsenic $[2,14,18,19]$.

Unique nanoparticle properties, such as high specific surface area, redox activity and mobility, could potentially lead to unexpected environmental risk 3 , 20-22][. First, nanoparticles might cause physical restrains to microorganisms. Cell-adsorbed nanoparticles could increase cellular weight and reduce mobility or, in algae and cyanobacteria, could reduce light available for photosynthesis [23]. Second, up-taken nanoparticles may catalyze specific intracellular reactions 
and harm cell metabolism. While common toxins show dose and mass-dependent effect on microorganism, a redox active nanoparticle may repeat its catalytic activity over and over again [6].

On the other hand, iron belongs to essential nutritious elements in most organisms and is usually not directly bioavailable. Thus, microorganisms developed several strategies involving solubilization of $\mathrm{Fe}^{3+}$ by extracellular acidification or the release of iron-chelating compounds followed by active uptake of $\mathrm{Fe}^{2+}$ or $\mathrm{Fe}^{3+}$-chelates across plasma membrane by endocytosis. Such mechanisms could enable the nanoiron to enter the living cells.

Several field studies on nanoiron suggest that its application could be beneficial for anaerobic microorganisms [24, 25]. The authors hypothesized that potential decrease, slight $\mathrm{pH}$ increase and production of hydrogen gas and also iron ion at the remediation site should favour the growth of microorganisms, which could accelerate biodegradation. Contrary, zero-valent nanoiron corrodes in the presence of oxygen or water to $\mathrm{Fe}^{2+}$, which could produce hydroxyl radicals via Fenton reaction (see part 3.1) and harm cellular DNA, proteins and lipids. The excess of intracellular iron could cause membrane depolarization and acidification of cytoplasm leading to disruption of homeostasis [26]. In addition, iron oxide particles strongly bind trace metals [27] and can increase toxicity or bioaccumulation of other contaminants. Thus, there is a large discussion on nanoparticle fate in the natural environment.

\section{Iron-induced oxidative stress in prokaryotic and eukaryotic microorganisms}

The oxidative stress is a situation caused by high intracellular concentrations of reactive oxygen species (ROS) which is microbial cell unable to deal with [11, 28]. ROS includes extremely unstable superoxide radicals, hydroxyl radicals and freely diffusible and relatively long-lived hydrogen peroxide that all can be generated exogenously or intracellularly from various sources. For example, ROS are normally produced during both prokaryotic and eukaryotic metabolism in mitochondria, chloroplasts, peroxisomes or in cytosol mainly as a by-product of aerobic respiration [29].

Presence of iron significantly influences the ROS level. When nanoiron oxides $\left(\mathrm{Fe}_{2} \mathrm{O}_{3}\right)$ were added to a cell culture, ROS levels increased 50 times comparing to control without nanoiron addition [30]. Interestingly, nanoiron $\left(\mathrm{Fe}_{2} \mathrm{O}_{3}\right)$ and soluble $\mathrm{Fe}$ salt $\left(\mathrm{FeCl}_{3}\right)$ caused similar level of oxidative injury to mussel gills, which could imply that nanoparticles have not special impact on this organism comparing to microscale iron [31].

Cells under severe oxidative stress, i.e. exposed to high ROS concentrations, show various dysfunctions of membrane lipids, proteins and DNA [3, 11]. Moreover, enhanced ROS generation in mitochondria can initiate mechanism described as ROS-induced ROS-release which triggers the opening of mitochondrial channels and leads to collapse of the mitochondrial membrane potential and a temporary increased ROS generation by the electron transfer chain leading to severe cell damage or death [32]. Thus, aerobic organisms 
developed complex defense and repair system [9, 10]. In addition, some microorganisms have strict regulation of iron assimilation to prevent an excess of free intracellular iron [13].

\subsection{Fenton reaction leading to oxidative stress}

Zero-valent nanoiron could react with either water or oxygen to produce ferrous or ferric iron (Reaction 1 and 2). Both redox reactions occur in the location where the nanoiron is applied or directly in the microorganism. The latter situation is possible because nanoiron is able to disrupt the lipopolysaccharides and proteins in outer cell membrane and enter the cell [33]. Alternatively, iron oxides on the shell of nZVI might enable endocytosis, when the $\mathrm{pH}$ is above isoelectric point and the shell is negatively charged. Iron oxide nanoparticles can also directly diffuse through the cell membrane [34].

Redox-active iron, originated from nanoiron materials, may in the cells enhance generation of more reactive hydroxyl radicals from less reactive hydrogen peroxide via the Fenton chemistry (Reaction 7; [8]).

$$
\mathrm{Fe}^{2+}+\mathrm{H}_{2} \mathrm{O}_{2} \rightarrow \mathrm{Fe}^{3+}+\mathrm{OH}^{\cdot}+\mathrm{OH}^{-}
$$

Ferrous iron could be oxidized to ferric iron and be then available to react with superoxide radical and start the reaction again:

$$
\begin{gathered}
\mathrm{Fe}^{2+}+\mathrm{OH}^{\cdot} \rightarrow \mathrm{Fe}^{3+}+\mathrm{OH}^{-} \\
\mathrm{Fe}^{3+}+\mathrm{O}_{2}^{\cdot-} \rightarrow \mathrm{Fe}^{2+}+\mathrm{O}_{2}
\end{gathered}
$$

Ferric iron could also react with peroxide radicals to form superoxide radical:

$$
\mathrm{Fe}^{3+}+\mathrm{H}_{2} \mathrm{O}_{2} \rightarrow \mathrm{Fe}^{2+}+\mathrm{OOH}^{\cdot}+\mathrm{H}^{+} \rightarrow \mathrm{Fe}^{2+}+2 \mathrm{H}^{+}+\mathrm{O}_{2}^{\cdot-}
$$

Furthermore, when $\mathrm{H}_{2} \mathrm{O}_{2}$ is in excess, the $\mathrm{Fe}^{2+}$ generated with the Reaction 10 can enter the Fenton reaction (Reaction 7) and produce more ROS.

\subsection{Oxidative stress in bacteria}

Oxidative stress in bacteria caused by ROS has been studied extensively over past decades [35]. However, very limited number of studies has been focused on nanoparticles and their role in ROS generation in bacteria.

Recently, Auffan et al. [36] examined the effect of 1-hour presence of nanoparticulate $\mathrm{Fe}_{2} \mathrm{O}_{3}, \mathrm{Fe}_{3} \mathrm{O}_{4}$ and $\mathrm{nZVI}$ on a wild type and a mutant bacterium Escherichia coli. The transmission electron microscopy analysis showed morphological changes of bacterial cells and also changes of nZVI shape. The iron nanoparticles were adsorbed on the cell surface, but did not enter the cells of $E$. coli. The authors suggest that the nanoparticles might cause oxidative stress 
via ROS generation and Fenton reaction as demonstrated using a mutant strain of $E$. coli without protective SOD enzymes. Further, the oxidative stress in $E$. coli can result from ROS the disturbance of the electronic and/or ionic transport chains due to the strong affinity of the nanoparticles for the cell membrane [36].

Similar results of nZVI toxicity on E. coli described Lee et al. [33]. The highest toxicity of nZVI was found in anaerobic condition, while in presence of oxygen, nZVI showed lower toxicity. Significant E. coli inactivation was detected in concentrations of nZVI above 60 and $70 \mathrm{mg} \mathrm{L}^{-1}$ in deaerated and aerated conditions, respectively. Under aerated conditions, nZVI oxidize and precipitate on the reactive surface of $\mathrm{nZVI}$ which might cause reduced reactivity and, thus toxicity. In anaerobic conditions, $\mathrm{Fe}^{2+}$ nanoparticles can contribute to ROS production, because $\mathrm{Fe}^{2+}$ is not rapidly oxidized to $\mathrm{Fe}^{3+}$. $\mathrm{Fe}_{2} \mathrm{O}_{3}$ nanoparticles were not toxic for $E$. coli in concentration of $9 \mathrm{mg} \mathrm{L}^{-1}$ and microscale ZVI was not toxic in concentration as high as $1 \mathrm{~g} \mathrm{~L}^{-1}$. The cell membrane was visibly disrupted by nZVI. Iron, as a strong reductant, might induce decomposition of functional groups in the membrane proteins and lipopolysaccharides, or nZVI could be oxidized by intracellular oxygen, leading to oxidative damages via the Fenton reaction. Most probably, more nZVI penetrated into the cells through the disrupted membranes causing further physical damages [33].

Bacillus subtilis use nitric oxide for protection against oxidative stress [37]. Nitric oxide can suppress the Fenton reaction by inhibiting cysteine reduction of ferric iron. Cysteine is the main reducing agent that drives the Fenton reaction in E. coli [38] as well as in B. subtilis. Moreover, nitric oxide boosts the activity of catalase which is an iron-heme enzyme involved in $\mathrm{H}_{2} \mathrm{O}_{2}$ scavenging. Nitric oxide thus helps to keep redox homeostasis and protect the cell during rapid metabolic changes. To date, bacterial nitric oxide synthases have been found only in Gram-positive bacteria [37].

\subsection{Oxidative stress in cyanobacteria}

Production of ROS constitutes a severe risk to photosynthetic organisms such as cyanobacteria and algae, because a common source of superoxide radicals is photosynthesis [26]. Mitochondria and chloroplasts have intensive electron fluxes which also contain higher oxygen and metal ion concentrations and therefore both organelles are more vulnerable to oxidative stress. Interestingly, cyanobacteria have different redox regulation system comparing to higher plants; for instance, most of cyanobacteria have catalatic activity, while mitochondria do not.

Oxidative stress in cyanobacteria is usually caused by irradiation [39]. Actually, there is no information on directly iron-induced oxidative stress in cyanobacteria. Because iron is rather scarce in water environment, its investigation has been mainly focused on iron limitation and acquisition by cyanobacteria. For example, nitrogen-fixing cyanobacteria require extensive amounts of iron. Iron could be sequestered from ambient environment by lowmolecular weight chelating compounds, siderophores, which transport iron into 
the cell [39]. The iron-siderophore complex contains $\mathrm{Fe}^{3+}$ form and serves as internal iron pool.

\subsection{Oxidative stress in algae}

The direct effect of nanoiron particulates on microscopic algae has not been studied yet. In a rare situation when dissolved iron is in excess, it might induce oxidative stress which affect algal growth and have negative impact for natural phytoplankton. Estevez et al. [40] studied the effect of surplus redox-active iron in oxidative stress of Chlorella vulgaris. When culture medium was supplemented with $500 \mu \mathrm{M}$ of iron, the cells shoved elevated number of membrane lipid peroxidation and other oxidative stress signs. In addition, morphology of $C$. vulgaris was affected, probably due to harmful effect on photosynthesis due to elevated ROS. On the other hand, C. vulgaris culture was able to adapt to mild oxidative stress by production of antioxidants, particularly $\alpha$-tocopherol, ascorbate and thiols [40]. Similarly, freshwater unicellular alga Euglena gracilis was able to respond to increasing $\mathrm{FeSO}_{4}$ loading with increasing total antioxidant activity that scavenged most of generated hydroxyl radicals.

Short-term exposition of green unicellular alga Chlamydomonas reinhardtii to selected metals caused elevated ROS production [41]. Iron was added at several environmentally relevant concentrations that did not directly affect photosynthesis in C. reinhardtii. Notably, iron induced maximal ROS production within redox-active metals (the final hierarchy was as follows: $\mathrm{Fe}^{3+}>\mathrm{Ag}^{+}>\mathrm{Cu}^{2+}$ $>\mathrm{Cr}^{6+}$ ).

Increasing ROS concentration in unicellular alga Emiliana huxley caused by viral infection started programmed cell death [42]. However, a certain threshold value of ROS has to be passed before the process leading to cell death begins. Up to this threshold value, E. huxley employed successfully cell-defense system.

\section{Summary}

Although it was proved that nanoiron has the potential to create oxidative stress in microorganisms, there are currently no scenarios which would indicate that this effect will become a significant problem. Here should be pointed out that a typical study of nanoiron effect on various organisms lasts from several hours to few days, while long term approach is needed. The ROS generation can be the result of exposure of reduced iron particles to a cell or a catalytic process which generates ROS until the nanoparticles are degraded. Such processes might not be fully recognized in short term experiments. Moreover, results might vary with different nanoparticle size. Nanoparticles smaller than $30 \mathrm{~nm}$ have exponentially more number of atoms on their surface than larger nanoparticles and thus show different physico-chemical properties.

The ROS generation and oxidative stress was not particularly examined in all studied species and cell cultures; still, oxidative damage was found in E. coli and Mytilus cells. The toxic response was uneasy to compare, because physico- 
chemical parameters varied in each of tested organisms or cell cultures. Under air saturation, nZVI was oxidized by oxygen and caused less harm comparing to non-aerated culture. In some experiments, nanoiron caused only slightly lowered cell viability (about 20\%). The evaluation and comparison of toxic responses would help normalizing it with uptake of nanoparticles and their state of agglomeration.

Here, it should be highlighted that none of the above studies on nanoiron was performed at in situ conditions. All experiments were carried out in cell cultures in a laboratory. Therefore, we have only limited indicia about the real effect of nanoiron in natural soil or water environment. The nanoiron potential to generate ROS and oxidative stress depends on nanoiron coatings, mobility, size, aggregation, physico-chemical parameters which is influenced by many factors, e.g. organic matter in the environment. For example, natural organic matter improved the mobility of nZVI in a sand medium due to sorption of the organic matter on the nZVI, resulting in reduced sticking coefficient. The nanoiron coating, besides mobility improving, might weaken or even stop its toxic effect as was showed.

To conclude, much more studies are needed on exposition of nanoiron leading to oxidative stress in soil and freshwater microorganisms. It is evident that research to date only little uncovered what might be the nanoiron fate in natural environment.

\section{Acknowledgement}

This material is based upon work supported by the Czech Ministry of Education under Grant 1M0554.

\section{References}

[1] Zhang W-X 2003. Nanoscale iron particles for environmental remediation: An overview. Journal of Nanoparticle Research 5: 323-332.

[2] Li X, Elliott DW, and Zhang W. 2006. Zero-Valent Iron Nanoparticles for Abatement of Environmental Pollutants: Materials and Engineering Aspects. Critical Reviews in Solid State and Materials Sciences, 31:111122.

[3] Klaine SJ, Alvarez PJJ, Batley GE, Fernandes TF, Handy RD, Lyon DY, Mahendra SY, McLaughlin MJ, Lead JR 2008. Nanomaterials in the environment: behavior, fate, bioavailability and effects. Environmental Toxicology and Chemistry 27 (9):1825-1851.

[4] Oberdörster G., Oberdörster E., Oberdörster J. 2005. Nanotoxicology: An Emerging Discipline Evolving from Studies of Ultrafine Particles. Environ Health Perspect 113:823-839.

[5] Shah V. and Belozerova I. 2008. Influence of Metal Nanoparticles on the Soil Microbial Community and Germination of Lettuce Seeds. Water Air Soil Pollut. DOI 10.1007/s11270-008-9797-6 
[6] Limbach LK, Grass RN, Stark WJ 2009. Physico-Chemical Differences Between Particle- and Molecule-Derived Toxicity: Can We Make Inherently Safe Nanoparticles? Chimia 63:38-43.

[7] Buffle J. 2006. The key role of environmental colloids/nanoparticles for sustainability of life. Environment \& Chemistry, 3, 155-158.

[8] Fenton H. J. H. 1894. Oxidation of tartaric acid in presence of iron. Journal of the Chemical Society, Transaction 65, 899-910.

[9] Fridovich I. 1978. The biology of oxygen radicals. Science 201:875-880.

[10] Imlay J. A., and Fridovich I. 1991. Assay of Metabolic Superoxide Production in Escherichia coli. J. Biol. Chem. 266: 6957-6965.

[11] Davies KJA 2000. Oxidative Stress, Antioxidant Defenses, and Damage Removal, Repair, and Replacement Systems. IUBMB Life, 50: 279-289.

[12] Nel A, Xia T, Madler L, Li N 2006. Toxic potential of materials at the nanolevel. Science 311:622-627.

[13] Touati D. 2000. Iron and oxidative stress in bacteria. Arch Biochem Biophys. 373(1):1-6.

[14] Ponder MS, Darab JG, Mallouk TE 2000. Remediation of Cr(VI) and Pb(II) Aqueous Solutions Using Supported, Nanoscale Zero-valent Iron. Environmental Science \& Technology 34 (12), 2564-2569.

[15] Schrick, B.; Hydutsky, B.W.; Blough, J.L.; Mallouk, T.E. 2004. Delivery vehicles for zerovalent metal nanoparticles in soil and groundwater. Chem. Mater. 16, 2187-2193.

[16] Darab JG, Amonette AB, Burke DSD, Orr RD, Ponder SM, Schrick B,Mallouk TE, Lukens WW, Caulder DL, Shuh DK. 2007. Removal of pertechnetate from simulated nuclear waste streams using supported zerovalent iron. Chem. Mater. 19: 5703-5713.

[17] Kim HJ, Phenrat T, Tilton RD, Lowry G. 2009. Fe0 Nanoparticles Remain Mobile in Porous Media after Aging Due to Slow Desorption of Polymeric Surface Modifiers. Environ. Sci. Technol. 43, 3824-3830.

[18] Zhang W-X, Elliott DW. 2006. Applications of iron nanoparticles for groundwater remediation. Remediation 16:7-21.

[19] Kanel, S. R.; Nepal, D.; Manning, B.; Choi, H. 2007. Transport of surfacemodified iron nanoparticle in porous media and application to arsenic(III) remediation. J. Nanopart. Res. 9 (5), 725-735.

[20] Maynard, A. D., Aitken, R. J., Butz, T.; Colvin, V., Donaldson, K., Oberdorster, G., Philbert, M. A., Ryan, J., Seaton, A., Stone, V., Tinkle, S. S., Tran, L., Walker, N. J., Warheit, D. B. 2006. Safe handling of nanotechnology. Nature 444, 267-269.

[21] Handy RD, Kammer F, Lead JR, Hassellov M, Owen R, Crane M 2008. The ecotoxicology and chemistry of manufactured nanoparticles. Ecotoxicology 17:287-314.

[22] Navarro E, Baun A, Behra R, Hartmann NB, Filser J, Miao A-J, Quigg A, Santschi PH, Sigg L 2008b. Environmental behavior and ecotoxicity of engineered nanoparticles to algae, plants, and fungi. Ecotoxicology 17:372386. 
[23] Navarro E., Piccapietra F, Wagner B, Marconi F., Kaegi R., Odzak N., Sigg L., Behra R. 2008a. Toxicity of Silver Nanoparticles to Chlamydomonas reinhardtii. Environ. Sci. Technol. 42, 8959-8964. [24] Elliott D. and W.Zhang, 2001. Field assessment of nanoparticles for groundwater treatment. Environ. Sci. Technol. 35, 4922-4926.

[24] Elliott D. and W. Zhang, 2001. Field assessment of nanoparticles for groundwater treatment. Environ. Sci. Technol. 35, 4922-4926.

[25] Glazier R., R. Venkatakrishnan, F. Gheorghiu, L. Walata, R. Nash \& W. Zhang, 2003. Nanotechnology takes root. Civil Engineering 73(5), 64-69.

[26] Pinto E, Sigaud-Kutner TCS, Leitao MAS, Okamoto OK, Morse D, Colepicolo P 2003. Heavy metal-induced oxidative stress in algae. J. Phycol. 39:1008-1018.

[27] Madden AS, Hochella MF, Luxton TP 2006. Insights for size-dependent reactivity of hematite nanomineral surfaces through $\mathrm{Cu}^{2+}$ sorption. Geochim Cosmochim Acta 70:4095-4104.

[28] Farr, S. B., and T. Kogoma. 1991. Oxidative stress responses in Escherichia coli and Salmonella typhimurium. Microbiol. Rev. 55:561-585.

[29] Stowe DF, Camara AKS 2009. Mitochondrial Reactive Oxygen Species Production in Excitable Cells: Modulators of Mitochondrial and Cell Function. Antioxidants \& Redox Signaling 11(6): 1373-1414.

[30] Limbach LK, Wick P, Manser P, Grass RN, Bruinink A, Stark WJ 2007. Exposure of Engineered Nanoparticles to Human Lung Epithelial Cells: Influence of Chemical Composition and Catalytic Activity on Oxidative Stress. Environ. Sci. Technol. 41: 4158-4163.

[31] Kádár E, Lowe DM, Solé M, Fisher AS, Jha AN, Readman JW, Hutchinson TH 2009. Uptake and biological responses to nano-Fe versus soluble $\mathrm{FeCl}_{3}$ in excised mussel gills. Anal Bioanal Chem. DOI 10.1007/s00216-0093191-0

[32] Zorov DB, Juhaszova M, Sollott SJ 2006. Mitochondrial ROS-induced ROS release: an updated review. Biochim Biophys Acta 1757(5-6):509-17.

[33] Lee C, Kim JY, Lee WII, Nelson KL, Yoon J and Sedlak DL 2008. Bactericidal Effect of Zero-Valent Iron Nanoparticles on Escherichia coli. Environ Sci Technol. 2008 July 1; 42(13): 4927-4933

[34] Verma A, Stellacci F 2009. Effect of Surface Properties on NanoparticleCell Interactions. Small. DOI: 10.1002/smll.200901158

[35] Wang S-W, Chen C-Y, Tseng JT, Liang H-S, Chen S-C, Hsieh C, Chen Y, Chen C-C 2009. orf4 of the Bacillus cereus sigB Gene Cluster Encodes a General Stress-Inducible Dps-Like Bacterioferritin. J Bacter 191:45224533.

[36] Auffan M, Achouak W, Rose J, Chaneac C, Waite DT, Masion A, Woicik J, Wiesner, MR, Bottero JY 2008. Relation between the redox state of iron based nanoparticles and their cytotoxicity towards Escherichia coli. Environmental Science and Technology 42 (17):6730-6735.

[37] Gusarov I, Nudler E 2005. NO-mediated cytoprotection: Instant adaptation to oxidative stress in bacteria. PNAS 102:13855-13860. 
[38] Park S, Imlay JA 2003. High Levels of Intracellular Cysteine Promote Oxidative DNA Damage by Driving the Fenton Reaction. J. Bacteriol. 185:1942-1950.

[39] Wilhelm SW 1995. Ecology of iron-limited cyanobacteria: a review of physiological responses and implications for aquatic systems. Aquatic Microbial Ecology 9:295-303.

[40] Estevez MS, Malanga G, Puntarulo S 2001. Iron-dependent oxidative stress in Chlorella vulgaris. Plant Sci 161:9-17.

[41] Szivák I, Behra R, Sigg L 2009. Metal-induced reactive oxygen species production in Chlamydomonas reinhardtii (Chlorophyceae). J Phycol 45:427-435.

[42] Evans C, Malin G, Mills GP, Wilson WH 2006. Viral infection of Emiliana huxley (Prymnesiophyceae) leads to elevated production of reactive oxygen species. J. Phycol. 42:1040-1047 